\title{
Presença de agrotóxicos na atmosfera e risco à saúde humana: uma discussão para a Vigilância em Saúde Ambiental
}

\author{
Presence of pesticides in atmosphere and risk to human health: \\ a discussion for the Environmental Surveillance
}

Gustavo dos Santos Souza ${ }^{1}$

Luciana Cristina Alves da Costa ${ }^{1}$

Alana Coelho Maciel ${ }^{1}$

Fábio David Vasconcelos Reis ${ }^{1}$

Ysabely de Aguiar Pontes Pamplona ${ }^{1}$

${ }^{1}$ Departamento de Vigilância em Saúde Ambiental e Saúde do Trabalhador, Secretaria de Vigilância em Saúde, Ministério da Saúde. Setor de Rádio e Televisão Norte (SRTV) 701/Via W5 Norte/ Edifício PO 700, $6^{\circ}$. 70719-040 Brasília DF Brasil.gustavo.ssouza@ saude.gov.br

\begin{abstract}
Brazil is the main consumer of pesticides in the world. Large-scale use of these products is likely to contaminate major environmental compartments and expose more people to their toxic effects. Therefore, this literature review was carried out to seek supporting elements for a qualified discussion about the performance of Environmental Health Surveillance (ES) within the Brazilian Unified Health System (SUS) related to air contamination by pesticides and health risks. Twelve papers were selected and analyzed in this literature review. Of these, only one was published in a specialized public health journal. Notwithstanding this, two epidemiological studies published in the field of environmental sciences investigated the association between air contaminated by pesticides and specific outcomes such as non-Hodgkin's lymphoma (NHL) and amyotrophic lateral sclerosis (ALS). Our findings reflect the lack of studies addressing such issue by public health. The discussion on air contamination by pesticides and potential risks to human health should be expanded by Brazilian science in order to further increase knowledge on the subject and support the ES performance capacity.
\end{abstract}

Key words Pesticides, Air pollution, Environmental health, Public Health Surveillance
Resumo O Brasil é o principal consumidor de agrotóxicos do mundo. $O$ uso em larga escala destes produtos é capaz de contaminar os principais compartimentos ambientais e expor um maior número de pessoas a seus efeitos tóxicos. Portanto, realizou-se esta revisão de literatura com o objetivo de buscar subsídios para uma discussão qualificada sobre a atuação da Vigilância em Saúde Ambiental (VSA) no âmbito do Sistema Único de Saúde relacionada com a contaminação atmosférica por agrotóxicos e riscos à saúde. Doze artigos foram selecionados e analisados nesta revisão de literatura. Destes, apenas um foi publicado em periódico especializado na área da saúde pública. Apesar disso, dois estudos epidemiológicos publicados na área das ciências ambientais investigaram a associação entre o ar contaminado por agrotóxicos e desfechos específicos como, linfoma não Hodgkin (LNH) e esclerose lateral amiotrófica (ELA). Nossos achados refletem a carência de estudos abordando o tema pela saúde pública. A discussão sobre a contaminação atmosférica por agrotóxicos e riscos potenciais à saúde humana deve ser ampliada pela ciência brasileira, a fim de aprofundar o conhecimento sobre o assunto e respaldar a capacidade de atuação da VSA.

Palavras-chave Praguicidas, Poluição do ar, Saúde ambiental, Vigilância em Saúde Pública 


\section{Introdução}

O aumento da produtividade, a forte presença da monocultura, a mecanização do campo, o agronegócio de exportação e o consumo de agrotóxicos são características da chamada "modernização agrícola” brasileira iniciada nas décadas de 1960 e $1970^{1}$. No entanto, a evolução desse modelo agrícola até os tempos atuais tem sido responsável por impactos e danos ao meio ambiente e à saúde pública ${ }^{2}$.

O Programa Nacional de Defensivos Agrícolas (PNDA), lançado em 1975, com base numa política oficial de governo de incentivo ao consumo de agrotóxicos, concorreu para a intensificação do uso destes produtos no país. A referida política fomentou, então, a adoção de medidas como isenção de impostos e taxas de importação, além da ampliação do crédito agrícola subsidiado ${ }^{3}$.

Nos anos de 1990, a indústria agrícola brasileira orientada para o mercado e focada no lucro fez crescer o consumo de agrotóxicos. Em 2008, o Brasil se tornou, portanto, o principal consumidor mundial de agrotóxicos. Esse fato, combinado com a deficiência no gerenciamento e controle do consumo por parte dos órgãos ambientais, resultou em um cenário nacional preocupante, tanto do ponto de vista ambiental, quanto de saúde pública, foco desta revisão.

Quando utilizados, os agrotóxicos podem facilmente desviar sua finalidade primária de combate às espécies-alvo, também conhecidas como "pragas". A toxicidade destes produtos está diretamente relacionada com os efeitos não desejáveis observados em outros organismos vivos, comunidades, ecossistemas e com a contaminação dos principais compartimentos ambientais: água, solo e $\mathrm{ar}^{4-7}$.

Os agrotóxicos se propagam facilmente no meio ambiente, sendo capazes de atingir a atmosfera e contaminar as imediações do local de aplicação graças a seu potencial de volatização a partir do solo, água e superfície vegetal (propriedade físico-química inerente aos agrotóxicos, que varia segundo o princípio ativo $)^{5,8}$. Outros atributos físico-químicos e mecanismos que incluem a incineração de lixo contaminado, temperatura, condições meteorológicas e tipo de manejo desses produtos, também podem estar relacionados à contaminação do ar por agrotóxicos 9 .

No ano 2000, a Fundação Nacional de Saúde (FUNASA), órgão do Ministério da Saúde, por meio do Decreto no 3.450/2000, inicia oficialmente no Brasil o processo de implantação da Vigilância em Saúde Ambiental (VSA) no SUS, centrado na reforma dos Centros de Controle de Zoonose e estruturação do Sistema de Informação da Qualidade da Água para Consumo Humano (SISAGUA). A partir desse ponto, algumas reestruturações institucionais foram implementadas, novos instrumentos normativos surgiram, a fim de ajustar a configuração da VSA para o modelo que está vigorando na atualidade e que contempla a vigilância de populações expostas aos agrotóxicos ${ }^{10}$.

A partir da Instrução Normativa no 01, da Secretaria de Vigilância em Saúde (SVS), do Ministério da Saúde, instituída no ano de 2005, a Coordenação Geral de Vigilância em Saúde Ambiental (CGVAM), anteriormente exercida no âmbito da Funasa, se reorganizou, assumindo uma estrutura técnica baseada na gestão do risco: (i) Vigilância da Qualidade da Água para Consumo Humano (VIGIAGUA); (ii) Vigilância em Saúde de Populações Expostas a Contaminantes Químicos (VIGIPEQ), focado em substâncias químicas prioritárias (agrotóxicos, benzeno, chumbo, amianto e mercúrio), atualmente envolvendo também as atividades do VIGISOLO (áreas contaminadas); (iii) a Vigilância de populações expostas à poluição atmosférica (VIGIAR), hoje desvinculado do VIGIPEQ; e (iv) Vigilância em Saúde Ambiental dos Riscos Associados aos Desastres (VIGIDESASTRES), englobando o VIGIFIS (relacionado aos fatores físicos) e também o VIGIAPP (relacionado a acidentes com produtos perigosos $)^{11}$.

O desenvolvimento e a aplicação de métodos para detectar a presença de agrotóxico no ar não consistem num assunto novo no campo das ciências ambientais. Assim como o risco para o meio ambiente e para a saúde humana decorrente da contaminação por agrotóxicos vêm sendo investigados ao longo dos anos, não se tratando, por conseguinte, de uma pauta inédita para a ciência.

Contudo, a problemática dos agrotóxicos no contexto da Vigilância em Saúde tem focado tradicionalmente na saúde do trabalhador, solo e água. Nesse sentido, impõe-se a necessidade de iniciar a discussão da matéria, a fim de fomentar o aprimoramento das medidas de Vigilância em Saúde Ambiental para grupos populacionais expostos ao ar contaminado por agrotóxicos.

Destarte, a dispersão de agrotóxicos no ar consiste em uma matéria transversal que carece de diálogo permanente entre as áreas técnicas VIGIPEQ e VIGIAR para o desenvolvimento de material técnico-científico que subsidie a construção de políticas públicas adequadas para o fortalecimento da VSA no âmbito federal. Logo, o escopo primordial da VSA diz respeito à ins- 
trumentalização do SUS para o planejamento e a execução de ações voltadas para a promoção da saúde, a prevenção e o controle dos danos associados aos fatores ambientais, sob a ótica da integralidade.

Apesar da relevância desta temática para a Vigilância em Saúde Ambiental no que diz respeito ao risco para saúde humana, monitoramento ambiental e rotas de ingresso de tais substâncias no organismo de indivíduos expostos, sobretudo daqueles pertencentes a grupos populacionais mais vulneráveis (crianças, idosos e trabalhadores), observa-se uma carência de estudos brasileiros versados nessa questão.

O escopo desta revisão não se limita a explorar estudos cuja contaminação do ar por agrotóxicos tenha ocorrido por meio de processos de pulverização e derivas dele resultante. Tampouco, pretende buscar desfechos de saúde específicos potencialmente associados à contaminação por agrotóxicos. A motivação para a realização deste estudo consiste em expandir a compreensão dos mecanismos de contaminação da matriz ambiental "ar" e seus efeitos para a saúde humana no âmbito da Vigilância em Saúde Ambiental.

Portanto, o objetivo desta revisão bibliográfica é levantar e analisar as publicações científicas dos últimos cinco anos sobre a contaminação do ar por agrotóxicos, os efeitos à saúde humana e possíveis impactos para a saúde pública, no intuito de aprofundar a reflexão sobre a formulação de estratégias de Vigilância em Saúde Ambiental no país sobre o tema, bem como a capacidade de promover uma atuação qualificada e sustentada por evidências científicas.

\section{Métodos}

Trata-se de uma revisão sistemática de literatura pautada na busca online em bases de informações para divulgação do conhecimento técnico e científico em ciências da saúde: PubMed - desenvolvido e mantido pelo National Center for Biotechnology Information (NCBI) dos Estados Unidos - e pela Biblioteca Virtual em Saúde (BVS)/Biblioteca Regional de Medicina (Bireme) - centro especializado da Organização Pan-Americana da Saúde/Organização Mundial da Saúde (OPAS/ OMS).

Preliminarmente, realizou-se uma busca por descritores de assunto que pudessem resultar em uma pesquisa com pouco ruído e que satisfizesse o objetivo primário do estudo. Assim, foram utilizados neste estudo os descritores "agrotóxicos", "poluentes do ar", "saúde pública", "risco" e seus correspondentes em língua inglesa.

A pesquisa utilizou o relacionamento dos termos e identificou 28 publicações, nos últimos cinco anos, oriundas exclusivamente do PubMed. A partir destas, recorreu-se à leitura dos resumos e títulos para orientar a seleção dos artigos a serem criteriosamente analisados e incluídos na revisão.

Nessa etapa, houve concordância dos autores, após ampla discussão, em excluir os estudos que se dedicaram a avaliar a exposição nos ambientes de trabalho, dada a especificidade de certos grupos ocupacionais, cuja natureza do trabalho pressupõe uma exposição maior do que a observada na população geral, como ocorre com agricultores e trabalhadores de indústrias produtoras de agrotóxico, por exemplo.

Dos 12 artigos previamente elegíveis para revisão, um não pôde ser acessado, restando 11 . Por outro lado, notou-se que a busca bibliográfica não foi capaz de captar um de três artigos publicados em série, provavelmente devido à especificidade do tema. Então, realizou-se uma busca independente pelo referido artigo. Depois de uma análise preliminar do artigo, os autores concordaram em inclui-lo nesta revisão, completando a série de três publicações. Assim, a revisão foi realizada com base no total de 12 artigos ( $\mathrm{n}$ = 12), uma vez que aquele artigo relevante foi adicionado isoladamente aos 11 incluídos de antemão.

Por fim, realizou-se a leitura crítica dos 12 artigos incluídos no estudo, os quais foram analisados individualmente por cada um dos autores, segundo critérios de originalidade, relevância e adequação ao propósito deste estudo (Figura 1).

$\mathrm{Na}$ análise dos estudos incluídos foram realizadas comparações das informações disponíveis em cada um deles. A apresentação e a discussão dos resultados obtidos foram centradas nas seguintes perspectivas: potenciais efeitos à saúde, avaliação da exposição e monitoramento ambiental do ar contaminado por agrotóxico.

\section{Resultados}

A busca eletrônica identificou 28 estudos. Destes, 12 artigos foram previamente selecionados, sendo eliminado um deles, de origem chinesa, por não estar publicado em língua portuguesa ou inglesa. Além disso, o referido artigo não se encontrava disponível nas bases a que se teve acesso na condução deste estudo. Em contrapartida, um 


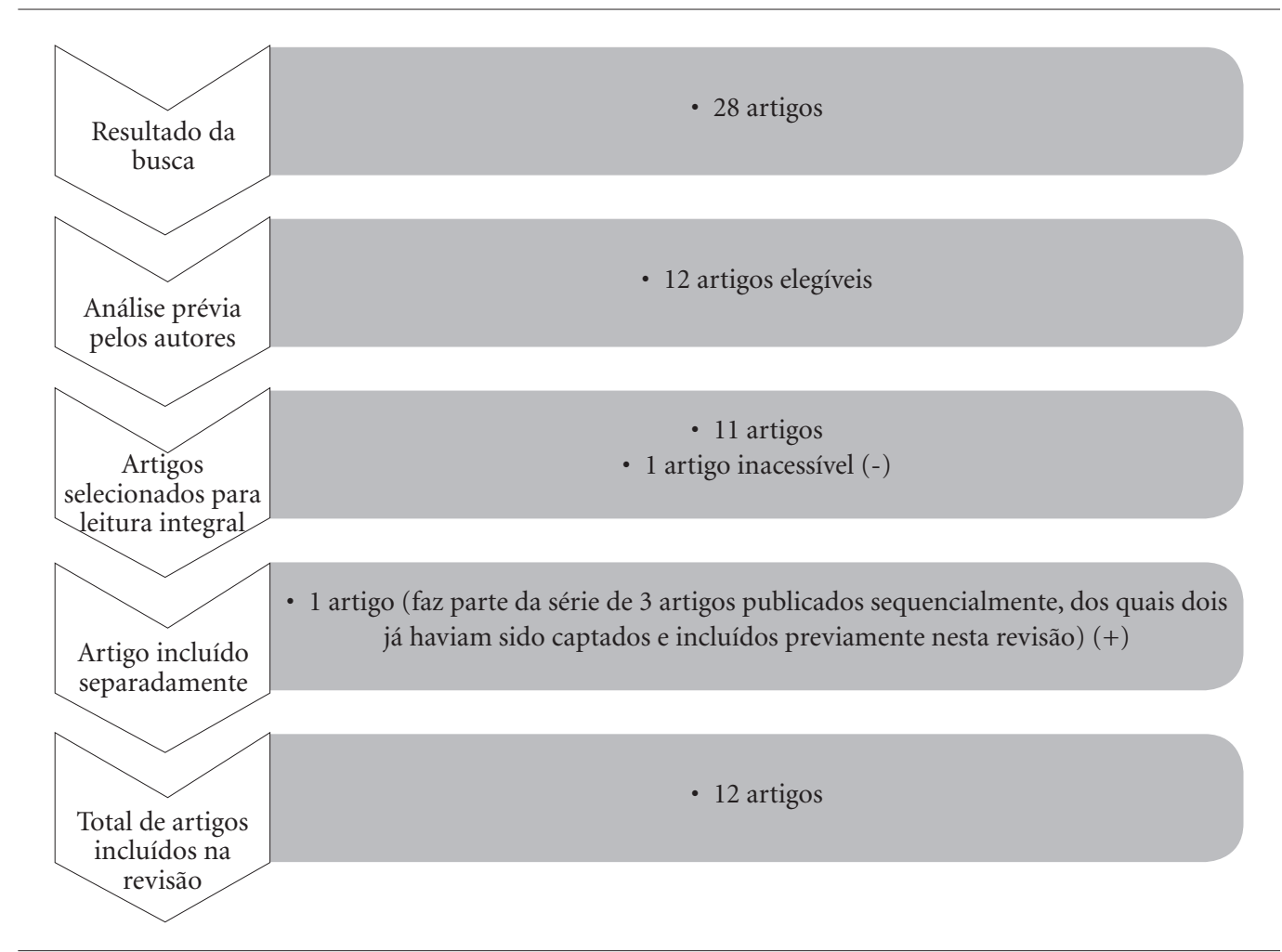

Figura 1. Fluxograma mostrando critérios e decisões tomadas em cada etapa de seleção dos estudos contemplados na revisão bibliográfica.

Fonte: Elaborado pelos autores.

artigo previamente excluído pelos mecanismos de busca e relacionado a outros dois desta revisão foi adicionado por último.

Finalmente, dos 12 trabalhos incluídos na revisão, seis foram originários dos Estados Unidos da América ${ }^{12-17}$ um da Austrália ${ }^{18}$, um da França $^{19}$, um da Armênia ${ }^{20}$, um de Portugal $^{21}$ e dois do Paquistão ${ }^{22,23}$. Estes, publicados em periódicos especializados nas áreas das ciências ambientais $(\mathrm{n}=9)$, da saúde $(\mathrm{n}=1)$ e toxicologia $(\mathrm{n}=2)$ (Quadro 1).

Observou-se que o único trabalho publicado na área da saúde compreendeu uma revisão de literatura abordando conceitos gerais em saúde ambiental e os possíveis fatores de risco ambiental para o desenvolvimento de câncer, entre eles a poluição do ar, apontado pelo autor como exemplo de associação causal bem estabelecida pela literatura ${ }^{18}$.

Curiosamente, dois estudos epidemiológicos do tipo caso-controle que buscaram associação entre exposição do ar contaminado por agrotóxicos não foram publicados em periódicas da área de saúde pública, comumente observado em investigações com tal objetivo e abordagem ${ }^{17,19}$.

Um deles ${ }^{19}$ buscou associação entre organoclorados (OC), proveniente de uma usina de incineração em Besançon, França, e o desenvolvimento do linfoma não Hodgkin (LNH). Dos OCs avaliados, o Beta-hexaclorociclohexano [Odds ratios $(\mathrm{OR})=1,05$; Intervalo de confiança (IC) 95\%: 1,00-1,2] e o DDT (OR = 1,20; IC 95\%: 1,01-1,45) foram associados com LNH. Contudo, outro estudo de mesma abordagem conduzido por Malek et al. ${ }^{17}$ não encontrou associação entre agrotóxico e desenvolvimento de esclerose lateral amiotrófica (ELA).

Assim como esses, outros sete artigos ${ }^{12,13,15,20-23}$ abordaram a temática da contaminação do ar por agrotóxicos a partir da perspectiva das ciências ambientais (monitoramento ambiental e análise e avaliação de risco).

Muito embora a metodologia para avaliação do impacto e risco de exposição frequentemente observada nestes estudos inclua de alguma maneira análises de interesse da saúde pública, 
Quadro 1. Principais características dos estudos incluídos na revisão bibliográfica.

\begin{tabular}{|c|c|c|c|c|c|}
\hline $\begin{array}{c}\text { Autores } \\
\text { (ano)/país }\end{array}$ & Título do artigo & Periódico & Tipo de estudo & Objetivo & Principais resultados \\
\hline $\begin{array}{l}\text { Stewart } \\
\text { BW (2012)/ } \\
\text { Austrália }^{18}\end{array}$ & $\begin{array}{l}\text { Priorities } \\
\text { for cancer } \\
\text { prevention: } \\
\text { lifestyle } \\
\text { choices versus } \\
\text { unavoidable } \\
\text { exposures }\end{array}$ & Lancet Oncol & $\begin{array}{l}\text { Revisão de } \\
\text { Literatura } \\
\text { (Considerações do } \\
\text { autor) }\end{array}$ & $\begin{array}{l}\text { Elucidar por } \\
\text { meios científicos, } \\
\text { os fatores de } \\
\text { risco ambiental, } \\
\text { “exposições } \\
\text { inevitáveis", } \\
\text { associados } \\
\text { ou não ao } \\
\text { desenvolvimento } \\
\text { do câncer, a fim } \\
\text { de discutir a } \\
\text { necessidade de } \\
\text { implementação } \\
\text { de medidas } \\
\text { preventivas. }\end{array}$ & $\begin{array}{l}\text { Há uma relação bem estabelecida } \\
\text { na literatura entre a poluição do } \\
\text { ar e o risco de desenvolvimento } \\
\text { do câncer de pulmão. Por isso, a } \\
\text { redução na emissão de poluentes } \\
\text { no ar constitui uma medida } \\
\text { urgente de controle do câncer } \\
\text { nos países em desenvolvimento, } \\
\text { e também um problema para } \\
\text { países desenvolvidos. Quanto } \\
\text { aos agrotóxicos, o potencial } \\
\text { de causar câncer, bem como a } \\
\text { carcinogenicidade, não estão } \\
\text { bem estabelecidos para todas as } \\
\text { classes químicas. No entanto, é de } \\
\text { relevante interesse da saúde pública, } \\
\text { sobretudo para a população } \\
\text { exposta ocupacionalmente, e não } \\
\text { por meio da ingestão de alimentos } \\
\text { contaminados por agrotóxicos, } \\
\text { como supõe a sociedade em geral. } \\
\text { Ainda assim, com base no princípio } \\
\text { da precaução, o monitoramento e a } \\
\text { adoção de possíveis medidas para a } \\
\text { redução de resíduos nos alimentos } \\
\text { devem ser de interesse da saúde } \\
\text { pública. }\end{array}$ \\
\hline $\begin{array}{l}\text { Batterman } \\
\text { et al. } \\
(2012) / \\
\text { EUA }^{12}\end{array}$ & $\begin{array}{l}\text { Sources, } \\
\text { concentrations, } \\
\text { and risks of } \\
\text { naphthalene } \\
\text { in indoor and } \\
\text { outdoor air }\end{array}$ & Indoor Air & $\begin{array}{l}\text { Monitoramento } \\
\text { ambiental: } \\
\text { avaliação da } \\
\text { exposição }\end{array}$ & $\begin{array}{l}\text { Descrever a } \\
\text { distribuição } \\
\text { e fontes de } \\
\text { concentração de } \\
\text { naftaleno na fase } \\
\text { gasosa em quatro } \\
\text { comunidades } \\
\text { do Sudeste de } \\
\text { Michigan, EUA. }\end{array}$ & $\begin{array}{l}\text { Outdoor: a mediana da } \\
\text { concentração encontrada em } \\
\text { ambiente externo foi de } 0,15 \mu \mathrm{g} / \mathrm{m}^{3} \text {, } \\
\text { com discreto aumento observado } \\
\text { no período de tráfego intenso; } \\
\text { Indoor: a mediana da concentração } \\
\text { observada no longo prazo foi de } \\
0,89 \mu \mathrm{g} / \mathrm{m}^{3} \text {, com certa assimetria } \\
\text { nos valores encontrados. } 14 \% \\
\text { das casas avaliadas apresentaram } \\
\text { concentrações de naftaleno acima } \\
\text { de } 3 \mu \mathrm{g} / \mathrm{m}^{3}, \text { valor de referência para } \\
\text { efeitos crônicos não cancerígenos. } \\
\text { Excederam os } 10 \mu \mathrm{g} / \mathrm{m}^{3}, 8 \% \text {, mas } \\
\text { os valores alcançaram até } 200 \mu \mathrm{g} / \\
\mathrm{m}^{3} \text {. A estimativa do risco de câncer } \\
\text { foi, aproximadamente, da ordem } \\
\text { de } 1 \text { para dez mil, mas alcançou } \\
1 \text { em cem em algumas casas. } \\
\text { As principais fontes poluidoras } \\
\text { observadas referem-se ao uso } \\
\text { de naftaleno como repelente de } \\
\text { insetos, desorizador de ambientes e } \\
\text { proveniente de garagens acopladas } \\
\text { às casas. }\end{array}$ \\
\hline
\end{tabular}


Quadro 1. continuação

\begin{tabular}{|c|c|c|c|c|c|}
\hline $\begin{array}{c}\text { Autores } \\
\text { (ano)/país }\end{array}$ & Título do artigo & Periódico & Tipo de estudo & Objetivo & Principais resultados \\
\hline $\begin{array}{l}\text { Viel et al. } \\
(2011) / \\
\text { França }^{19}\end{array}$ & $\begin{array}{l}\text { Increased risk of } \\
\text { non-Hodgkin } \\
\text { Lymphoma } \\
\text { and serum } \\
\text { organochlorine } \\
\text { concentrations } \\
\text { among } \\
\text { neighbors of a } \\
\text { municipal solid } \\
\text { waste incinerator }\end{array}$ & $\begin{array}{l}\text { Environmental } \\
\text { International }\end{array}$ & Caso-controle & $\begin{array}{l}\text { Avaliar o risco de } \\
\text { desenvolver LNH } \\
\text { na população } \\
\text { exposta a tipos de } \\
\text { organoclorados } \\
\text { lançados no ar } \\
\text { por meio da } \\
\text { incineração de } \\
\text { resíduos sólidos } \\
\text { num município } \\
\text { da França, usando } \\
\text { a concentração } \\
\text { sérica do } \\
\text { agrotóxico } \\
\text { para avaliar a } \\
\text { exposição. }\end{array}$ & $\begin{array}{l}\text { Organoclorados associados ao } \\
\text { risco de desenvolver LNH: Beta- } \\
\text { hexaclorociclohexano (Odds ratios } \\
[\mathrm{OR}]=1,05 ;[\mathrm{IC}] 95 \%=1,00-1,2) ; \\
\mathrm{DDT}([\mathrm{OR}]=1,20 ;[\mathrm{IC}] 95 \%=1,01- \\
\text { 1,45); Outras espécies químicas } \\
\text { associadas ao risco aumentado para } \\
\text { LNH: Dioxinas, Furanos e PCBs }\end{array}$ \\
\hline $\begin{array}{l}\text { Segawa et } \\
\text { al. }(2014) / \\
\text { EUA }^{13}\end{array}$ & $\begin{array}{l}\text { Community } \\
\text { air monitoring } \\
\text { for pesticides. } \\
\text { Part 1: selecting } \\
\text { pesticides and a } \\
\text { community }\end{array}$ & $\begin{array}{l}\text { Environ Monit } \\
\text { Assess }\end{array}$ & $\begin{array}{l}\text { Desenvolvimento } \\
\text { e aplicação de } \\
\text { métodos específicos } \\
\text { de monitoramento } \\
\text { ambiental do ar }\end{array}$ & $\begin{array}{l}\text { Selecionar } \\
\text { agrotóxicos } \\
\text { relevantes para a } \\
\text { saúde humana, } \\
\text { assim como uma } \\
\text { comunidade } \\
\text { no estado da } \\
\text { Califórnia/EUA } \\
\text { para receber } \\
\text { uma estação de } \\
\text { monitoramento } \\
\text { de agrotóxicos no } \\
\text { ar, tendo por base } \\
\text { a participação } \\
\text { da sociedade, } \\
\text { critérios de } \\
\text { escolha objetivos } \\
\text { e transparentes. }\end{array}$ & $\begin{array}{l}\text { O estudo do California Department } \\
\text { of Pesticide Regulation (CDPR) } \\
\text { resultou em uma lista com os } 40 \\
\text { mais importantes agrotóxicos e } \\
\text { produtos de sua degradação, do } \\
\text { ponto de vista da Saúde Pública, } \\
\text { e viabilidade de monitoramento, } \\
\text { assim como uma comunidade: } \\
\text { Parlier, localizada no Vale de São } \\
\text { Joaquim/Califórnia, para receber } \\
\text { o monitoramento de agrotóxicos } \\
\text { presentes no ar por um ano. }\end{array}$ \\
\hline $\begin{array}{l}\text { Hengel \& } \\
\text { Lee }(2014) / \\
\text { EUA }^{14}\end{array}$ & $\begin{array}{l}\text { Community air } \\
\text { monitoring for } \\
\text { pesticides. Part } \\
\text { 2: multiresidue } \\
\text { determination } \\
\text { of pesticides } \\
\text { in air by gas } \\
\text { chromatography } \\
\text { - mass } \\
\text { spectrometry, } \\
\text { and liquid } \\
\text { chromatography } \\
\text { - mass } \\
\text { spectrometry }\end{array}$ & $\begin{array}{l}\text { Environ Monit } \\
\text { Assess }\end{array}$ & $\begin{array}{l}\text { Descrição do } \\
\text { processo de } \\
\text { desenvolvimento } \\
\text { e validação de } \\
\text { método analítico } \\
\text { para determinação } \\
\text { de múltiplos } \\
\text { agrotóxicos no ar }\end{array}$ & $\begin{array}{l}\text { Desenvolver } \\
\text { métodos para } \\
\text { determinação } \\
\text { de múltiplos } \\
\text { agrotóxicos no ar }\end{array}$ & $\begin{array}{l}\text { As duas metodologias } \\
\text { desenvolvidas são comparáveis e } \\
\text { apropriadas para a determinação de } \\
\text { agrotóxico residual no ar }\end{array}$ \\
\hline
\end{tabular}


Quadro 1. continuação

\begin{tabular}{|c|c|c|c|c|c|}
\hline $\begin{array}{l}\text { Autores } \\
\text { (ano)/país }\end{array}$ & Título do artigo & Periódico & Tipo de estudo & Objetivo & Principais resultados \\
\hline $\begin{array}{l}\text { Wofford et } \\
\text { al. }(2014) / \\
\text { EUA }^{15}\end{array}$ & $\begin{array}{l}\text { Community air } \\
\text { monitoring for } \\
\text { pesticides. Part } \\
\text { 3: using health- } \\
\text { based screening } \\
\text { levels to evaluate } \\
\text { results collected } \\
\text { for a year }\end{array}$ & $\begin{array}{l}\text { Environ Monit } \\
\text { Assess }\end{array}$ & $\begin{array}{l}\text { Monitoramento } \\
\text { ambiental do ar } \\
\text { potencialmente } \\
\text { contaminado por } \\
\text { agrotóxicos e seus } \\
\text { subprodutos }\end{array}$ & $\begin{array}{l}\text { Avaliar a } \\
\text { potencial } \\
\text { exposição da } \\
\text { população } \\
\text { residente em } \\
\text { Parlier/Califórnia } \\
\text { a agrotóxicos } \\
\text { e produtos de } \\
\text { sua degradação } \\
\text { presentes no ar }\end{array}$ & $\begin{array}{l}\text { Os residentes de Parlier estiveram } \\
\text { expostos durante um ano de } \\
\text { monitoramento a } 19 \text { tipos } \\
\text { de agrotóxicos, com picos de } \\
\text { concentração diária que variaram } \\
\text { de } 16 \text { a } 23,6 \mathrm{ng} / \mathrm{m}^{3} \text {. - O diazinon } \\
\text { excedeu o Screening Level (SL), } \\
\text { medida utilizada pelo estudo } \\
\text { para estimar níveis de exposição, } \\
\text { tendo por base a probabilidade } \\
\text { de não ocorrer efeitos adversos } \\
\text { à saúde não relacionados com } \\
\text { câncer. - O 1,3 Dicloropeno } \\
\text { excedeu os valores atribuídos a } \\
\text { seu Cancer Potency Value, medida } \\
\text { utilizada para estimar o potencial } \\
\text { carcinogênico com base no Sistema } \\
\text { de Informação de risco Intragrado } \\
\text { proposto pela US EPA. }\end{array}$ \\
\hline $\begin{array}{l}\text { Dvorská et } \\
\text { al. (2012)/ } \\
\text { Armênia }^{20}\end{array}$ & $\begin{array}{l}\text { Obsolete } \\
\text { pesticide storage } \\
\text { sites and their } \\
\text { POP release into } \\
\text { the environment } \\
\text { - an Armenian } \\
\text { case study }\end{array}$ & $\begin{array}{l}\text { Environ Sci } \\
\text { Pollut Res }\end{array}$ & $\begin{array}{l}\text { Avaliação de } \\
\text { compartimentos } \\
\text { ambientais, } \\
\text { inclusive o ar, } \\
\text { e alimentos } \\
\text { potencialmente } \\
\text { contaminados } \\
\text { por agrotóxicos } \\
\text { classificados } \\
\text { como poluentes } \\
\text { orgânicos } \\
\text { persistentes (POP) } \\
\text { em aterros e seus } \\
\text { antigos locais de } \\
\text { armazenamento. }\end{array}$ & $\begin{array}{l}\text { Analisar quatro } \\
\text { áreas da Armênia } \\
\text { selecionadas por } \\
\text { conter resíduos } \\
\text { de POP, quanto } \\
\text { à potencial } \\
\text { exposição } \\
\text { humana, risco } \\
\text { à saúde e } \\
\text { capacidade de } \\
\text { disseminação de } \\
\text { contaminantes } \\
\text { para a matriz } \\
\text { ambiental em } \\
\text { escala local }\end{array}$ & $\begin{array}{l}\text { Nas amostras coletadas em regiões } \\
\text { de antigos aterros e depósitos de } \\
\text { agrotóxicos de quatro localidades } \\
\text { distintas da Armênia, todas } \\
\text { apresentaram algum grau de } \\
\text { contaminação ambiental. Em } \\
\text { Jrarat, uma das localidades } \\
\text { investigadas por ser antigo } \\
\text { depósito e centro de distribuição } \\
\text { de agroquímicos (agrotóxicos } \\
\text { e fertilizantes) do governo, } \\
\text { encontrou-se contaminação } \\
\text { do solo por agrotóxicos nas } \\
\text { imediações das instalações } \\
\text { carreados e dispersos na forma } \\
\text { de pó pelo vento (256,91 mg Kg-1 } \\
\text { p,p'-DDT). Hipótese mais plausível } \\
\text { do que a volatização neste caso, } \\
\text { segundo os autores. Ainda nesta } \\
\text { localidade, as amostras coletadas } \\
\text { de ar se mostraram altamente } \\
\text { contaminada por DDT (soma dos } \\
\text { isômeros igual a } 4320,4 \text { ng disc } \\
\text { 1) com decréscimo da poluição } \\
\text { à medida que se distanciava das } \\
\text { ruínas do armazém contaminado. } \\
\text { Ainda nesta região, detectou-se } \\
\text { poluição do ar por evaporação } \\
\text { do lindano e B-endossulfano. Em } \\
\text { Nubarashen, local do aterro de } \\
\text { resíduos de agrotóxicos, constatou- } \\
\text { se poluição do ar por HCH (2376,8 } \\
\text { ng disc -1). }\end{array}$ \\
\hline
\end{tabular}


Quadro 1. continuação

\begin{tabular}{|c|c|c|c|c|c|}
\hline $\begin{array}{c}\text { Autores } \\
\text { (ano)/país }\end{array}$ & Título do artigo & Periódico & Tipo de estudo & Objetivo & Principais resultados \\
\hline $\begin{array}{l}\text { Ratola et } \\
\text { al. }(2014) / \\
\text { Portugal }^{21}\end{array}$ & $\begin{array}{l}\text { Biomonitoring } \\
\text { of pesticides by } \\
\text { pine needles } \\
\text { - Chemical } \\
\text { scoring, risk of } \\
\text { exposure, levels } \\
\text { and trends }\end{array}$ & $\begin{array}{l}\text { Science of } \\
\text { the Total } \\
\text { Environment }\end{array}$ & $\begin{array}{l}\text { Avaliação } \\
\text { ambiental do ar } \\
\text { contaminado } \\
\text { por agrotóxico } \\
\text { com base no } \\
\text { biomonitoramento }\end{array}$ & $\begin{array}{l}\text { Determinar os } \\
\text { níveis de } 18 \text { tipos } \\
\text { de agrotóxicos } \\
\text { por meio da } \\
\text { análise folhas de } \\
\text { pinheiros (Pinus } \\
\text { pinea) coletadas } \\
\text { em } 12 \text { localidades } \\
\text { diferentes de } \\
\text { Portugal }\end{array}$ & $\begin{array}{l}18 \text { agrotóxicos foram selecionados } \\
\text { entre } 70 \text { para avaliação de } \\
\text { contaminação do ar por meio } \\
\text { do biomonitoramento usando } \\
\text { folhas de pinheiro em } 12 \text { regiões } \\
\text { de Portugal. Destes, o molinato, } \\
\text { o pirimicarbe, o paratiom- } \\
\text { etil, ametrim, prometrim e } \\
\text { pendimetalina foram classificados } \\
\text { como de muito alto e alto risco } \\
\text { de exposição. Além disso, a } \\
\text { contaminação do ar se mostrou } \\
\text { maior em áreas rurais, seguida da } \\
\text { industrial e urbana. }\end{array}$ \\
\hline $\begin{array}{l}\text { Mahmood } \\
\text { et al. } \\
(2014) / \\
\text { Paquistão }{ }^{22}\end{array}$ & $\begin{array}{l}\text { Human health } \\
\text { risk assessment } \\
\text { and dietary } \\
\text { intake of } \\
\text { organochlorine } \\
\text { pesticides } \\
\text { through air, } \\
\text { soil and food } \\
\text { crops (wheat } \\
\text { and rice) along } \\
\text { two tributaries } \\
\text { of river Chenab, } \\
\text { Pakistan } \\
\end{array}$ & $\begin{array}{l}\text { Food and } \\
\text { Chemical } \\
\text { Toxicology }\end{array}$ & $\begin{array}{l}\text { Avaliação } \\
\text { ambiental e } \\
\text { toxicológica }\end{array}$ & $\begin{array}{l}\text { Avaliar os } \\
\text { potenciais } \\
\text { riscos para a } \\
\text { saúde humana } \\
\text { relacionados à } \\
\text { contaminação por } \\
\text { organoclorados. }\end{array}$ & $\begin{array}{l}\text { Foram avaliadas } 6 \text { amostras de } \\
\text { ar na província de Punjab, no } \\
\text { Paquistão, cujas concentrações } \\
\text { organoclorados variaram de } 123 \\
\text { a } 625 \mathrm{pg} \mathrm{m}^{-3} \text {. No entanto, excesso } \\
\text { de risco para a saúde (Hazard } \\
\text { Ratio) foi observado somente nas } \\
\text { amostras de trigo e arroz. }\end{array}$ \\
\hline $\begin{array}{l}\text { Kumar et } \\
\text { al. }(2014) / \\
\text { EUA }^{16}\end{array}$ & $\begin{array}{l}\text { Glyphosate- } \\
\text { rich air samples } \\
\text { induce IL-33, } \\
\text { TSLP and } \\
\text { generate IL- } \\
13 \text { dependent } \\
\text { airway } \\
\text { inflammation }\end{array}$ & Toxicology & Toxicológico & $\begin{array}{l}\text { Explorar os } \\
\text { mecanismos } \\
\text { de indução } \\
\text { do glifosato } \\
\text { na patologia } \\
\text { pulmonar } \\
\text { utilizando } \\
\text { modelos com } \\
\text { ratos e com } \\
\text { amostras } \\
\text { ambientais reais }\end{array}$ & $\begin{array}{l}\text { A exposição dos ratos ao ar rico } \\
\text { em glifosato ou glifosato sozinho } \\
\text { aumentou nos pulmões: eosinófilos } \\
\text { e neutrófilos, degranulação de } \\
\text { mastócitos e produção de IL-33, } \\
\text { TSLP, IL-13 e IL-5. Amostras de } \\
\text { ar da fazenda ricas em glifosato } \\
\text { (coletados em período de } \\
\text { pulverização do herbicida) ou o } \\
\text { glifosato sozinho se mostraram } \\
\text { capazes de induzir a inflamação } \\
\text { pulmonar IL-13-dependente e } \\
\text { promover citocinas do tipo Th2. }\end{array}$ \\
\hline $\begin{array}{l}\text { Sultana et } \\
\text { al. }(2014) / \\
\text { Paquistão }\end{array}$ & $\begin{array}{l}\text { Investigation of } \\
\text { organochlorine } \\
\text { pesticides } \\
\text { from the Indus } \\
\text { Basin, Pakistan: } \\
\text { Sources, air- } \\
\text { soil exchange } \\
\text { fluxes and risk } \\
\text { assessment }\end{array}$ & $\begin{array}{l}\text { Science of } \\
\text { the Total } \\
\text { Environment }\end{array}$ & $\begin{array}{l}\text { Avaliação } \\
\text { ambiental }\end{array}$ & $\begin{array}{l}\text { Avaliar o nível de } \\
\text { contaminação por } \\
\text { organoclorados } \\
\text { (OCs) e seu } \\
\text { potencial de } \\
\text { fazer a migração } \\
\text { entre os } \\
\text { compartimentos } \\
\text { ambientais: ar- } \\
\text { solo, além de } \\
\text { avaliar os riscos } \\
\text { para a saúde na } \\
\text { bacia do Indus/ } \\
\text { Paquistão }\end{array}$ & $\begin{array}{l}\text { Organoclorados mais prevalentes } \\
\text { na região estudada, inclusive no } \\
\text { ar: DDTs e HCHs. Concentração } \\
\text { média de DDTs mais elevada no } \\
\text { ar de regiões agrícolas ( } 743 \mathrm{pg} / \\
\text { m3), embora tenha se mostrado } \\
\text { espacialmente presente em toda a } \\
\text { área estudada. O risco de câncer } \\
\text { encontrado na população residente } \\
\text { de Indus Basin foi elevado ( RC > } \\
1 \text { X 10-6) }\end{array}$ \\
\hline
\end{tabular}


Quadro 1. continuação

\begin{tabular}{|l|l|l|l|l|l|}
\hline $\begin{array}{c}\text { Autores } \\
\text { (ano)/país }\end{array}$ & Título do artigo & \multicolumn{1}{|c|}{ Periódico } & Tipo de estudo & \multicolumn{1}{c|}{ Objetivo } & \multicolumn{1}{c|}{ Principais resultados } \\
\hline $\begin{array}{l}\text { Malek et } \\
\text { al. (2015)/ } \\
\text { EUA }^{17}\end{array}$ & $\begin{array}{l}\text { Exposure to } \\
\text { hazardous } \\
\text { air pollutants } \\
\text { and the risk of } \\
\text { amyotrophic } \\
\text { lateral sclerosis }\end{array}$ & $\begin{array}{l}\text { Environmental } \\
\text { Pollution }\end{array}$ & Caso-controle & $\begin{array}{l}\text { Investigar a } \\
\text { relação entre } \\
\text { a exposição } \\
\text { a poluentes } \\
\text { atmosféricos } \\
\text { perigosos } \\
\text { com potencial } \\
\text { neurotóxico } \\
\text { (PAPs) e } \\
\text { esclerose lateral } \\
\text { amiotrófica } \\
\text { (ELA) }\end{array}$ & $\begin{array}{l}\text { Apesar de ter encontrado um } \\
\text { risco significativamente elevado } \\
\text { para ELA decorrente da exposição } \\
\text { residencial a solventes aromáticos } \\
\text { em 2002 (OR }=5,03,95 \% \text { CI: } \\
1,29,19,53), \text { não foi encontrada } \\
\text { associação entre ELA e agrotóxicos. }\end{array}$ \\
\end{tabular}

Fonte: Elaborado pelos autores.

como, por exemplo, a estimativa do risco ou potencial carcinogênico relacionado à exposição a agrotóxicos, segundo metodologias de avaliação de risco propostas por agências internacionais do setor ambiental ou da saúde, como a United States Environmental Protection Agency (US EPA) e a Organização Mundial da Saúde (OMS).

\section{Discussão}

A motivação deste trabalho deveu-se à necessidade de compreender melhor as potenciais rotas, fontes, mecanismos e prováveis impactos na saúde de populações potencialmente expostas ao ar contaminado por agrotóxicos, a fim de iniciar as discussões entre pesquisadores, gestores e atores interessados, dada a relevância deste tema para a consolidação das ações de Vigilância em Saúde Ambiental no país.

Igualmente importante seria um aprofundamento na questão abordada, a fim de considerar a possibilidade de elaboração e adoção de futuras medidas de Vigilância em Saúde Ambiental, com vistas à mitigação ou eliminação do risco, prevenção e controle.

O setor agropecuário é o principal responsável pelas emissões de agrotóxicos no meio ambiente. Como mostrou Ratola et al. ${ }^{21}$, as áreas rurais são potencialmente mais poluídas do que as próximas a indústrias, seguida da zona urbanas, em termos de contaminação do ar por agrotóxicos.

Municípios cercados por grandes plantações ou próximos à zona rural, como ocorre em regiões do Brasil com predomínio do modelo agrícola baseado na monocultura e voltado para o abastecimento do mercado internacional, devem ser prioritários também do ponto de vista da Vigilância em Saúde Ambiental, inclusive quanto à contaminação do ar. Isso porque a distribuição do risco ocorre de modo desigual no território, atingindo sobretudo as comunidades rurais ou urbanas influenciadas por este tipo de agricultura.

No início da busca, esperou-se deparar na literatura científica com uma quantidade suficiente de artigos que explorassem a temática da contaminação do ar por agrotóxicos relacionados ao modo de aplicação - deriva de pulverização de agrotóxicos em plantações -, contaminando populações e áreas ao redor. Esse exemplo pode ser relacionado ao episódio ocorrido no município mato-grossense de Lucas do Rio Verde em março de 2006, referido como acidente rural ampliado, que trouxe a tônica do problema para a saúde pública brasileira, culminando com a publicação em periódicos científicos ${ }^{24}$.

Porém, a pesquisa bibliográfica que contemplasse a contaminação ambiental do ar, excluindo os ambientes específicos de trabalho - exposição ocupacional - se mostrou escassa e retornou 12 artigos nos últimos cinco anos. Surpreendentemente, nenhum deles se referia a estudos realizados no Brasil, revelando um contrassenso, dado o modelo de processo produtivo agrícola predominante no país, com alta dependência de agroquímicos (agrotóxicos e fertilizantes), como abordado anteriormente.

Em outros países, a poluição atmosférica por agrotóxicos é comumente abordada com base na análise por classes químicas específicas de agrotóxicos e possíveis efeitos à saúde a eles associados, e também não coloca o uso desses produtos 
na agroindústria associado à poluição do ar no cerne das investigações científicas.

Considerou-se neste estudo a definição legal de agrotóxicos vigente no Brasil. Assim, todos os estudos identificados exploram a contaminação do ar por agrotóxicos e os produtos de sua degradação, independentemente das fontes de emissão e meios pelos quais os agrotóxicos chegam à atmosfera.

Observou-se na análise dos resultados que as formas de poluição do ar por agrotóxicos variaram desde o uso doméstico como repelente de animais indesejáveis, desodorizador de ambiente à possível contaminação do ar por produtos da incineração de resíduo sólido.

Do mesmo modo, os efeitos à saúde investigados nos estudos analisados contemplaram o risco para desenvolvimento do câncer em geral ${ }^{18}$ e neoplasias mais específicas ${ }^{19}$, como o linfoma não Hodgkin (LNH).

A rota de exposição mais provável mostrada nos estudos avaliados, ainda que tacitamente, foi por vias aéreas com a inalação do ar contaminado com algum agrotóxico ou subproduto. Embora a possibilidade de exposição por via dérmica ou por ingestão de alimentos contaminados não tenha sido descartada.

Nossos achados refletem a carência de estudos abordando o tema pelo setor saúde. No tocante ao Brasil, onde os lucros gerados pelo setor agropecuário representam uma importante contribuição para o cenário econômico nacional vigente, a carência de estudos científicos e o descaso do setor público com a população potencialmente exposta ao ar contaminado por agrotóxicos se mostra ainda mais preocupante.

Soma-se a isso a dificuldade do país de promover a migração adequada para um modelo agrícola mais sustentável, ao mesmo tempo em que seja capaz de produzir lucro, o que resultaria ainda em longos períodos de exposição pela população. Países desenvolvidos tendem a apresentar um sistema de monitoramento e vigilância mais avançado.

Como se percebeu neste trabalho, o desenvolvimento de novas técnicas e metodologias de monitoramento do ar contaminado por agrotóxicos vem sendo desenvolvido no mundo e apontam para um caminho a ser seguido pelo Brasil, tanto do ponto de vista acadêmico, quanto de aprimoramento das medidas do setor saúde, no que concerne à Vigilância em Saúde Ambiental.

A expansão da abordagem tradicional vigente - que foca nos riscos à saúde relacionados com a presença e contaminação do solo e da água por agrotóxicos, ou nos problemas ocupacionais decorrentes desse tipo de exposição química - para um modelo de vigilância ambiental em saúde mais abrangente que considera também a contaminação do ar é necessária no âmbito do SUS e não poderia iniciar de maneira diferente, que não por meio do levantamento bibliográfico envolvendo essa temática. 


\section{Colaboradores}

GS Souza trabalhou na concepção, delineamento metodológico, análise e interpretação dos resultados, redação e revisão do artigo. YAP Pamplona contribuiu na concepção, análise e interpretação dos resultados e revisão crítica do artigo. ACMaciel trabalhou na metodologia e análise dos resultados. FDV Reis participou na pesquisa bibliográfica e interpretação dos resultados. LCA Costa contribuiu na condução da revisão bibliográfica e análise dos resultados.

\section{Referências}

1. Porto MF, Milanez B. Eixos de desenvolvimento econômico e geração de conflitos socioambientais no Brasil: desafios para a sustentabilidade e a justiça ambiental. Cien Saude Colet 2009; 14(6):1983-1994.

2. Porto MF, Soares WL. Modelo de desenvolvimento, agrotóxicos e saúde: um panorama da realidade agrícola brasileira e propostas para uma agenda de pesquisa inovadora. Rev Bras Saúde Ocup 2012; 37(125):17-31.

3. Bull D, Hathaway D. Pragas e Venenos: Agrotóxicos no Brasil e no Terceiro Mundo. Petrópolis: Vozes, Oxfam, Fase; 1986.

4. van der Werf HMG. Assessing the impact of pesticides on the environment. Agric Ecosyst Environ 1996; 60(23):81-96.

5. Belden JB, Hanson BR, McMurry ST, Smith LM, Haukos DA. Assessment of the Effects of Farming and Conservation Programs on Pesticide Deposition in High Plains Wetlands. Environ Sci Technol 2012; 46(6):34243432.

6. Köck-Schulmeyer M, Ginebreda A, Postigo C, Garrido T, Fraile J, López de Alda M, Barceló D. Four-year advanced monitoring program of polar pesticides in groundwater of Catalonia (NE-Spain). Sci Total Environ 2014; 470-471:1087-1098.

7. Peres F, Oliveira-Silva JJ, Della-Rosa HV, Lucca SR. Desafios ao estudo da contaminação humana e ambiental por agrotóxicos. Cien Saude Colet 2005; 10(Supl.):2737.

8. Coscollà C, Colin P, Yahyaoui A, Petrique O, Yusà V, Mellouki A, Pastor A. Occurrence of currently used pesticides in ambient air of Centre Region (France). Atmos Environ 2010; 44(32):3915-3925.

9. Breivik K, Alcock R, Li Y-F, Bailey RE, Fiedler H, Pacyna JM. Primary sources of selected POPs: regional and global scale emission inventories. Environ Pollut 2004; 128(1):3-16.

10. Brasil. Decreto no 3.450, de 9 de maio de 2000. Aprova o Estatuto e o Quadro Demonstrativo dos Cargos em Comissão e das Funções Gratificadas da Fundação Nacional de Saúde - FUNASA, e dá outras providências. Diário Oficial da União 2000; 10 maio.

11. Rohlfs DB, Grigoletto JC, Netto GF, Rangel CF. A construção da Vigilância em Saúde Ambiental no Brasil. Cad Saúde Colet 2011; 19(4):391-398.

12. Batterman S, Chin J-Y, Jia C, Godwin C, Parker E, Robins T, Max P, Lewis T. Sources, concentrations, and risks of naphthalene in indoor and outdoor air. Indoor Air 2012; 22(4):266-278.

13. Segawa R, Levine J, Neal R, Brattesani M. Community air monitoring for pesticides. Part 1: selecting pesticides and a community. Environ Monit Assess 2014; 186(3):1327-1341.

14. Hengel M, Lee P. Community air monitoring for pesticides - part 2: multiresidue determination of pesticides in air by gas chromatography, gas chromatography-mass spectrometry, and liquid chromatography-mass spectrometry. Environ Monit Assess 2014; 186(3):1343-1353.

15. Wofford P, Segawa R, Schreider J, Federighi V, Neal $\mathrm{R}$, Brattesani M. Community air monitoring for pesticides. Part 3: Using health-based screening levels to evaluate results collected for a year. Environ Monit Assess 2014; 186(3):1355-1370. 
16. Kumar S, Khodoun M, Kettleson EM, McKnight C, Reponen T, Grinshpun SA, Adhikari A. Glyphosate-rich air samples induce IL-33, TSLP and generate IL-13 dependent airway inflammation. Toxicology NIH Public Access 2014; 325:42-51.

17. Malek AM, Barchowsky A, Bowser R, Heiman-Patterson T, Lacomis D, Rana S, Ada Y, Talbott EO. Exposure to hazardous air pollutants and the risk of amyotrophic lateral sclerosis. Environ Pollut 2015; 197:181-186.

18. Stewart BW. Priorities for cancer prevention: Lifestyle choices versus unavoidable exposures. Lancet Oncol 2012; 13(3):e126-33.

19. Viel J-F, Floret N, Deconinck E, Focant J-F, De Pauw E, Cahn J-Y. Increased risk of non-Hodgkin lymphoma and serum organochlorine concentrations among neighbors of a municipal solid waste incinerator. Environ Int 2011; 37(2):449-453.

20. Dvorská A, Šír M, Honzajková Z, Komprda J, upr P, Petrlík J, Anakhasyan E, Simonyan L, Kubal M. Obsolete pesticide storage sites and their POP release into the environment - an Armenian case study. Environ Sci Pollut Res 2012; 19(6):1944-1952.

21. Ratola N, Homem V, Silva JA, Araújo R, Amigo JM, Santos L, Alves A. Biomonitoring of pesticides by pine needles - Chemical scoring, risk of exposure, levels and trends. Sci Total Environ 2014; 476-477:114-124.

22. Mahmood A, Malik RN, Li J, Zhang G. Human health risk assessment and dietary intake of organochlorine pesticides through air, soil and food crops (wheat and rice) along two tributaries of river Chenab, Pakistan. Food Chem Toxicol 2014; 71:17-25.

23. Sultana J, Syed JH, Mahmood A, Ali U, Rehman MYA, Malik RN, Li J5, Zhang G. Investigation of organochlorine pesticides from the Indus Basin, Pakistan: Sources, air-soil exchange fluxes and risk assessment. Sci Total Environ 2014; 497-498:113-122.

24. Pignati WA, Machado JMH, Cabral JF. Acidente rural ampliado: o caso das "chuvas" de agrotóxicos sobre a cidade de Lucas do Rio Verde - MT. Cien Saude Colet 2007; 12(1):105-114.

Artigo apresentado em 30/05/2017

Aprovado em 26/06/2017

Versão final apresentada em 19/07/2017 